\title{
MORAL E ALIENAÇÃO: UMA APROXIMAÇÃO ENTRE O JOVEM HEGEL E NIETZSCHE PELA RELIGIÃO
}

\section{MORAL AND ALIENATION: AN APPROXIMATION BETWEEN THE YOUNG HEGEL AND NIETZSCHE BY RELIGION}

Felipe B. Zandoná

\begin{abstract}
RESUMO: O presente trabalho pretende apresentar ao leitor uma aproximação entre a moral e a alienação a partir de um diálogo entre o jovem Hegel e Nietzsche. O objetivo geral do artigo é demonstrar - para além das divergências filosóficas - que o Hegel da juventude e Nietzsche possuem um cerne crítico comum no trato da moral. Como objetivo específico, o artigo pretende demonstrar que este cerne crítico da moral passa, primordialmente, pela crítica religiosa e, em especial pelo fenômeno da alienação. $\mathrm{Na}$ intenção de atingir os objetivos aqui traçados, tomaremos por base, inicialmente, a alienação como manifestada por Hegel nos seus escritos teológicos de juventude, em especial nas obras $O$ positivismo da religião cristã e $O$ espirito do cristianismo e seu destino. Importante será, na seqüência do trabalho, a crítica religiosa feita por Nietzsche na Genealogia da moral, já que possibilitará uma análise conjunta das duas filosofias e nos levará a um desfecho final do trabalho onde, como conclusão, pretenderá se demonstrar que os efeitos da alienação no jovem Hegel possuem claras semelhanças para com os efeitos da moral em Nietzsche.
\end{abstract}

Palavras-chave: Hegel. Nietzsche. moral. Alienação

\begin{abstract}
The pretensions of this work is to present to the lector an aproximation between the moral and the alienation from a dialogue between the young Hegel $\mathrm{e}$ Nietzsche. The article general objective is to demonstrate - beyond the filosofical variance - that the Young Hegel and Niteszche have a common critical core about the moral. As a specific objective, the article intends to demonstrate that this moral critical core passes by, primarily, by the religious criticism and, in special, by the alienation phenomenon. Intending to reach the objectives, we will take for basis, initialy, the alienation as manifestaded by Hegel in yours early theological writings, specialy in the works The Positivity of the Christian Religion and The Spirit of Chistianity and its Fate. Relevant is, in the sequence of the work, the religious criticism made by Nitezsche in Genalogy of Morals, since it will enable a joint analysis of the two phiolosophies and will take us to a final outcome where, as conclusion, intended to demonstrate that the effects of alienation in the young Hegel have clear similarities to the effects of moral in Nietzsche.
\end{abstract}

Keywords: Nietzsche. moral. Hegel. alieantion 


\section{INTRODUÇÃO}

Stephen Houlgate, em seu livro Hegel, Nietzsche e a crítica da metafísica, procedeu na tentativa de aproximação das filosofias de Hegel e Nitzsche através da metafísica. Nesta obra, o filósofo britânico deixou bem claro a dificuldade de aproximarmos duas filosofias aparentemente tão distintas e dois temperamentos igualmente distintos.

Hegel é um filósofo sistemático que coloca sua fé no rigoroso e metódico revelar-se da razão dialética, enquanto que Nietzsche é um assistemático, escritor altamente literário, o campeão dos aforismos e das metáforas coloridas e atraentes. (1986, p. 1)

Mas essa comparação, ou talvez este debate, que o próprio Houlgate procedeu através do tema da metafísica, apesar da dificuldade, faz sentido por várias outras vias. Como exemplo, Giles Deleuze justifica esta apoximação pelo próprio fato de Nietzsche considerar Hegel o primeiro alvo de suas investidas filosóficas, já Walter Kaufmann faz uma união entre Hegel e Nietzsche pelos conceitos alemães de aufheben e sublimieren ${ }^{1}$.

$\mathrm{Na}$ esteira de tais exemplos, tentaremos aproximar o jovem Hegel de Nietzsche. Na sua juventude, Hegel não possuía uma filosofia tão rigorosa quanto viria a ter no futuro, flertou por muito tempo com o romantismo alemão e trabalhou fervorosamente com temas ligados a religião. Os estudos implicados neste artigo envolvem um debate entre aspectos das filosofias de Hegel e Nietzsche, em especial, os aspectos que tratam da alienação e da moral. Tentaremos aqui, ao longo dos capítulos, fazer uma leitura da moral em Nietzsche a partir do problema da alienação, como foi tratado pelo jovem Hegel, de uma perspectiva basicamente teológica.

A alienação é elemento central da filosofia de Hegel, ganhando contornos diferentes conforme sua filosofia foi amadurecendo. Aqui, serão utilizados como base de trabalho os escritos teológicos de juventude de Hegel, onde a alienação está

\footnotetext{
${ }^{1}$ Correspondente semântico: sublimar
} 
vinculada a uma crítica a prática religiosa judaico-cristã, aliada a uma moral de caráter positivo. É pertinente a utilização destes escritos teológicos de Hegel, pois é também em boa parte pela crítica da religião que Nietzsche vai travar sua luta contra a moral; aqui, utilizaremos a sua Genealogia da Moral, pois nesta obra Nietzsche descreve com precisão os fundamentos de toda a sua crítica moral.

Como conclusão, este trabalho apresenta a moral em Nietzsche como uma manifestação de efeitos semelhantes ao que, no jovem Hegel, se definiu por alienação. Ambas as críticas estão direcionadas a fragilidade, ou a incompetência de um sistema, ainda vigente, que impõe a moral por ela mesma - no caso de Nietzsche - ou como uma lei positiva - no caso do jovem Hegel - que é totalmente estranha a consciência natural do homem.

\section{A LUTA CONTRA A ALIENAÇÃO NO JOVEM HEGEL}

É impossível falarmos da alienação no jovem Hegel sem nos reportarmos a religião; seus escritos de juventude são eminentemente teológicos. As obras $O$ Positivismo da Religião Cristã e O Espirito do Cristianismo e Seu Destino, são expoentes da crítica Hegeliana aos fundamentos do Judaísmo, e ao caminho que o cristianismo tomou após a morte de Jesus Cristo. Mas o pano de fundo, ou o grande motivo desta crítica Hegeliana à religião, é a forma como ela trata da moral. Neste sentido, é importante fazer a leitura do que Hegel diz logo no início de $O$ Positivismo da Religião Cristã, no que diz respeito aos fundamentos da crítica da religião:

[...] Observo aqui que o princípio geral a ser estabelecido como base para todos os julgamentos sobre as diversas modificações, formas e espíritos da religião Cristã é este - que o objetivo e a essência de toda a verdadeira religião, inclusive a nossa religião, é a moralidade humana, e que todas as doutrinas mais detalhadas do cristianismo, todos os meios de propagá-las e todas as suas obrigações (sejam obrigações de crer ou obrigações de realizar ações) têm seu valor e sua santidade avaliados de acordo com sua finalidade ou com a distância da conexão com este fim. (HEGEL, 1961, p. 68) 
O que Hegel quer dizer, é que toda crítica religiosa deve partir da analise da adequação entre a prática religiosa e o espírito ou finalidade próprios desta religião; a finalidade da religião, para o filósofo alemão, é a própria moralidade humana. Mas tanto o judaísmo da época de Cristo quanto o Cristianismo pós Cristo se desviaram de seu fim, e em determinado ponto da história as suas finalidades passaram da moralidade humana para a moralidade como lei, o que Hegel critica como positivismo da lei moral; é o fato da lei tê-la, ela mesma, e seu estrito cumprimento como finalidade. O judaísmo da época de Cristo possuía como finalidade a estrita obediência a uma lei moral pré-estabelecida, imposta por Deus; era uma moral de submissão e escravidão, que o próprio Jesus Cristo combateu. Já o Cristianismo Eclesiástico - como manifestado após a morte de Jesus Cristo, - vai se transformando e ganhando elementos deste positivismo dogmático que remete ao judaísmo pré-cristão, até chegar ao ponto de, na modernidade Hegeliana, ter como finalidade a própria sustentação da igreja com instituição moral.

Quanto ao Judaísmo, Hegel dirá:

[...] como resultado desse sistema, a coisa mais sagrada, a saber, o serviço de Deus e da virtude, foi ordenada e comprimida em fórmulas mortas, e nada além do orgulho por essa obediência servil às leis não estabelecidas por si mesmas foi deixado ao espírito judaico, que já estava mortificado e amargurado pela sujeição do estado a uma potência estrangeira. (HEGEL, 1961, p. 68-69)

Quanto ao Cristianismo, Hegel reconhece o fato de que o dogmatismo proveniente dele é fruto de uma construção secular, que começou com a propagação da palavra de Cristo após sua morte. Desde então, cada vez mais o cristianismo original, como pregado por Jesus, passou a se afastar de uma moral humana, de essência afetiva, e passou a ser uma religião baseada em dogmas e superstições. Hegel chama seu estudo sobre a moral cristã, de "a história do dogma"

\footnotetext{
2 The history of dogma.
} 
A questão toda está em que medida o destino de cada tradição segue fiel ao seu espírito. No caso do Cristianismo, o seu destino trai o seu espírito: aquele da prática de seu fundador. (FEILER, 2015, p.28)

Semelhante é a crítica de Hegel dirigida a ética Kantiana que, para ele, também torna a moral uma lei positiva. O que determina os homens é uma lei de caráter transcendente, e o valor de uma ação moral não é tomado a partir do homem com ser moral no mundo, mas da moralidade com lei suprema, e o homem designado ao estrito cumprimento do imperativo categórico. Neste sentido, "Tanto a ética do Antigo Testamento quanto a Kantiana exaltam a ideia da lei moral e a implacável transcendência ao Absoluto".(KRONER, 1961, p. 10)

Mas como essa crítica religiosa é manifestação de uma luta do jovem Hegel contra a alienação do homem? A resposta é que, tanto a moral do judaísmo, como professado na época de Cristo, quanto a do Cristianismo após a morte de Cristo, e também a ética Kantiana, são manifestações de uma moral positiva. Esse positivismo significa a imposição da letra fria de uma lei moral que, por si só, não torna o homem consciente de sua moralidade, pelo contrário, faz com que o homem, no estrito cumprimento do dever que lhe é imposto se torne estranho ao seu próprio ser; é daí que decorre uma alienação, o uma divisão do homem. O que ele é, essencialmente, não é o que ele manifesta na prática. Se por um lado a lei moral positiva determina o comportamento do homem em detrimento de sua essência, por outro, este comportamento pré-determinado é divergente do que o próprio indivíduo, considerando suas particularidades, manifestaria caso não fosse obrigado do contrário. Daí decorre inevitavelmente o estranhamento e a alienação. O homem é alienado de si, pois a lei moral como estabelecida pelo outro, assim o exige. Em detrimento de seus sentimentos particulares e ao invés de manifestar a sua essência e consciência moral, manifesta uma moral estranha, e portanto, não se reconhece nos seus próprios atos. Tudo isso é sintetizado nesta breve passagem, que trata da alienação enquanto manifestada na fé cristã:

Hegel, por isso, a desmascara como produto do mundo imaginário da cultura moderna infiltrada sobretudo na moral cristã, condenada como uma existência inautêntica, pois reduz o Cristianismo à submissão a um código individual de conduta. O conteúdo de fé no qual se crê resulta 
externo ao crente, em vez de se incorporar ao ato próprio da fé. (FEILER, 2015, p. 48)

Portanto, a luta que Hegel trava com a religião e mesmo com a ética Kantiana, é a luta contra o fenômeno da alienação, uma luta, basicamente, contra uma má exteriorização dos sentimentos, contra o agir em desacordo com a consciência moral, motivado pelo estrito cumprimento de uma lei moral. Neste caso, a igreja Católica foi uma das mais bem-sucedidas forças de imposição dogmática, dominante ao longo de toda a história. Daí depreende-se a identidade das críticas religiosas de Hegel e Nietzsche, como veremos.

\section{A LUTA CONTRA A MORAL EM NIETZSCHE}

Na Genealogia da Moral, percebemos a grande luta que Nietzsche trava ao longo de sua vida; essa luta é contra a moral. Para Nietzsche os ideais de moralidade, como construídos e propagados ao longo da história, são fábricas de ressentimento e má consciência, que impedem o ser humano de viver em seu potencial máximo; a moral é uma grande doença que atinge a humanidade.

[...] precisamos de uma crítica dos valores morais, e antes disso precisamos questionar o próprio valor desses valores - e para isso é necessário o conhecimento das condições e circunstâncias das quais eles surgiram, sob as quais eles se desenvolveram e se deslocaram (a moral como conseqüência, como sintoma, como máscara, como tartufaria, como doença, como mal-entendido; mas também como causa, como remédio, como estimulante, como repressão, como veneno), e como esse conhecimento até agora não existia, nem mesmo foi desejado. (NIETZSCHE, 2017, p. 34, grifo nosso)

Nesta passagem, percebemos a importância para Nietzsche de uma grande genealogia crítica dos valores morais. Mas uma palavra utilizada por Nietzsche nesta citação é exemplificadora do sentido em que a moral trabalha no intuito de alienar o homem. Nietzsche utiliza a palavra tartufaria, e nos parece que não por acaso, já que a palavra se refere à comédia de Moliére, cujo protagonista, Tratufo, é um homem falso e hipócrita que se esconde atrás de uma mascara de profunda devoção religiosa. $\mathrm{Na}$ própria língua portuguesa o termo Tratufo possui um 
significado ligado à hipocrisia e a falsidade religiosa. Neste sentido que, à semelhança de Hegel, o processo de releitura crítica dos valores históricos da moral como feito por Nietzsche, passa por uma crítica aos alicerces religiosos da má consciência e do ressentimento. Nietzsche partilha com o jovem Hegel da crítica ao judaísmo, já que para ele, "os judeus eram aquele povo sacerdotal do ressentimento par excellence, a quem era inerente uma genialidade popular-moral sem igual". (NIETZSCHE, 2017, p. 82

Para Nietzsche, a moral tem uma função clara, a de tornar o ser humano algo de regular e previsível, ou seja, tornar o homem algo que ele não é por natureza. Para alienar o homem não foram medidos esforços nem poupados os sofrimentos, e uma grande forma de representar essa tentativa forçada de alterar a natureza humana foi o estabelecimento de códigos de conduta moral, ou seja, mais uma vez, temos aqui o dilema da lei moral positiva; Nietzsche chamará de "moralidade dos costumes", "[...] o ser humano foi realmente tornado previsível com a ajuda da moralidade dos costumes e da camisa de força social". (2017, p. 90) Nietzsche dirá ainda, que se trata aqui da "enfermiça amenização e moralização, graças às quais o animal 'ser humano' finalmente aprende a sentir vergonha de todos os seus instintos". (2017, p.95)

Diante destas fortes afirmações, e possível dizer que a moral em Nietzsche tem um claro papel, qual seja o de reprimir os afetos naturais do ser humano; essa repressão se fez, ao longo da história, por um processo de memorização forçada - e aqui temos um papel fundamental da religião - de preceitos e costumes morais; assim, a ação humana pôde se padronizar, o comportamento se tornou regular e previsível, construindo-se assim, o que Nietzsche chama de moral de rebanho. Mais uma vez, o homem é alienado de seu ser essencial, só que agora pela repressão da moral dos costumes, construída ao longo da história com a finalidade de determinar o comportamento do homem em um padrão passível de ser controlado; o homem já não é um individuo com potencial próprio, e sim mais um em um rebanho de iguais, onde já não pode se reconhecer.

\section{A MORAL COMO ALIENAÇÃO}


Como se percebe pelas leituras dos capítulos anteriores, tanto Hegel quanto Nietzsche compartilham de uma crítica à sistematização da moral em códigos de conduta fechados. Fazem isso, em boa parte, através da crítica histórica da moral judaico-cristã, que foi estabelecida sob um compilado de leis positivas, estranhas e mistificada. A crítica ao Cristianismo se torna paradigmática em ambas as filosofias, já que Hegel e Nietzsche partem do mesmo ponto de vista. O Cristianismo institucionalizado, a partir da morte de Cristo, na prática, tem como finalidade a sustentação de suas próprias leis, sob uma moral de submissão e temor. Neste sentido, a alienação, pra Hegel, é conseqüência prática de um processo de estranhamento interior do homem, causado por essa lei moral positiva, que lhe é imposta sem exigir qualquer tipo de compreensão, pelo contrário, exigindo uma obediência cega. Para Nietzsche a própria moral, em si, opera de uma forma bastante semelhante; é um obstáculo ao natural desenvolvimento do homem, inibe seus afetos e suas paixões, torna-o um ser artificial, um servo. O que isso produzirá, na prática do homem, é uma má exteriorização das vontades, uma atitude alienada, de um homem que é divido entre o que ele é (sua essência), e o que a lei moral positiva exige que ele seja (outra coisa que não ele mesmo). Neste sentido:

Com fim, em si mesma, a lei é positiva, distante do ser humano, frente à qual Hegel a critica como estranha. Essa mesma crítica Nietzsche endereça à lei como moral; um estranhamento da lei, do qual resulta uma similaridade nas críticas de Hegel e Nietzsche ao Cristianismo. (FEILER, 2015, p. 49)

Lukács, ao proceder a uma breve genealogia da alienação no jovem Hegel, mostra como esse já mencionado caráter de positividade da lei moral, é um elemento fundamental na produção de um comportamento alienado. Tanto a religião, como a própria sociedade moderna, foram aos poucos se tornando cada vez mais oprimidas por leis positivas, que distanciaram o homem do que ele é, e o aproximaram do que o mandamento legal diz que ele deve ser. A lei positiva é estranha, como "objetividade morta", ao ser subjetivo do homem, em especial, se distanciando da prática humana subjetiva. (LUKACS, 2018, p. 687) Tanto para o 
jovem Hegel como para Nietzsche, expoentes de um romantismo alemão, atacar este sistema fechado de leis, essa positividade moral dogmática é, ao mesmo tempo, uma tentativa de trazer de volta a beleza e o entusiasmo moral da religião popular grega e criar uma moral mais afetiva aos sentimentos primários do homem e aberta às constantes modificações do mundo.

O fundamento da alienação, como foi visto, é a positividade; a forma de uma lei moral impositiva que determina o agir do homem, distanciando-o ou estranhando-o de sua própria natureza. $\mathrm{O}$ individuo não se reconhece mais, pois seu agir é determinado por uma lei estranha, que o torna servo. Neste sentido, a positividade, como

Essa dimensão da lei, da qual se depreende uma moral, é um ponto comum nas críticas de Hegel e de Nietzsche, seja da moral vista como o momento dialético da exteriorização pelo deparar-se com o estranho, a lei, seja pela lei entendida como aquela instância autoritária e opressiva que põe o indivíduo na posição de passividade e subserviência. (FEILER, 2015, p. 7)

Então, para responder se a moral em Nietzsche tem os efeitos de uma alienação, é necessário passar pela crítica ao problema da positividade da lei moral. Os dois filósofos aqui estudados combatem cada um a seu modo, esse positivismo na moral que cinde o homem e que o aproxima forçosamente da lei e do dever quando ao mesmo tempo o distancia de quem ele realmente é. Em ambos os casos, tanto no jovem Hegel quanto em Nietzsche, esse distanciamento vai operar um estranhamento no homem, e uma má exteriorização de suas ações; no caso de Hegel, o homem estará alienado, no caso de Nietzsche, ele estará ressentido, duas palavras diferentes que representam o resultado de uma crítica muito semelhante.

Dois trechos selecionados, um da obra O Espirito do Cristianismo e seu Destino, do jovem Hegel, e outro da Genealogia da Moral de Nietzsche, nos dão uma pequena noção da semelhança que se opera em ambas as críticas filosóficas. De Nietzsche temos a artificialidade, a mentira e a falsidade do homem para com ele mesmo, promovida pela moralização: 


\begin{abstract}
Então essas "boas pessoas" estarão todas profundamente moralizadas, e em relação à sinceridade, frustradas e estragadas por toda a eternidade: qual delas ainda suportaria uma verdade sobre o "ser humano"!... Ou, perguntando-se mais concretamente: qual delas suportaria uma biografia autêntica!... (NIETZSCHE, 2017, p.218)
\end{abstract}

Do jovem Hegel, o trecho selecionado mostra como, na luta contra o positivismo da moral, o homem pode ir ao encontro de si mesmo:

Quando a subjetividade se opõe ao positivo, a neutralidade moral desaparece junto com seu caráter limitado. O homem se confronta consigo mesmo; seu caráter e suas ações se tornam o próprio homem. Ele só tem barreiras onde ele mesmo as erige, e suas virtudes são determinações que ele mesmo se fixa. (HEGEL, 1961, p. 224-225)

Estes dois trechos são paradigmáticos, pois mostram como as filosofias do jovem Hegel e de Nietzsche se aproximam até o ponto de se complementar. $\mathrm{Na}$ primeira citação, Nietzsche fala do homem que não suportaria olhar para sua própria biografia, caso esta fosse autêntica (não moralizada); não é esta uma manifestação do estranhamento do homem para consigo mesmo? Já na segunda citação, a do jovem Hegel, não há uma espécie de síntese reconciliatória? Onde o resultado da luta do homem contra a alienação perpetrada pelo positivismo da lei moral seria um reencontro com ele mesmo?

\title{
CONCLUSÃO
}

A resposta que esse trabalho tenciona a dar, é que sim. Pois considerando que, em ambas as filosofias, a moral apresenta um elemento estranhador, que afeta o homem consigo mesmo e suas ações, ambas operam numa alienação. A solução desta alienação passa, inevitavelmente, por uma inversão, onde a subjetividade do ser humano se tornará a finalidade da moral em detrimento de sua forma legal. Nietzsche é mais duro na luta contra a moral. Para ele, eventual solução para o problema da alienação passaria pela total abolição da moral. O resultado positivo, no entanto, para ambos os filósofos, é a possibilidade do homem não só suportar, 
mas reconhecer-se e reafirmar-se em sua própria biografia, com um ser autêntico e não alienado. 


\section{REFERÊNCIAS BIBLIOGRÁFICAS}

FEILER, A. F. Hegel e Nietzsche: a ética cristã concebida pelo amor e o destino. São Leopoldo: 1.ed. UNISINOS, 2015.

HEGEL, F. Early theological writings. Tradução para o inglês de T.M. Knox. Nova Iorque, Harper \& Brothers, 1961.

KRONER, R. Introdução. In: HEGEL, F. Early theological writings. Tradução de T. M. Knox. Nova Iorque, Harper \& Brothers, 1961.

LUKÁCS, G. O jovem Hegel e os problemas da sociedade capitalista. Tradução de Nélio Schneider. São Paulo, Boitempo, 2018.

NIETZSCHE, F. Genealogia da moral. Tradução de Inês A. Lohbauer, São Paulo: Martin Claret, 2017.

HOULGATE, S. Hegel, Nietzsche and the criticism of metaphysics. $1^{\text {a }}$ Ed. Nova Iorque. Cambridge University Press, 1986. 